\title{
O PENSAMENTO NA ATIVIDADE PRÁTICA: IMPLICAÇÕES NO PROCESSO PEDAGÓGICO
}

\author{
Maria Eliza Mattosinho Bernardes
}

\begin{abstract}
RESUMO. O estudo apresenta uma síntese teórica sobre a lógica e as formas de pensamento na atividade prática como decorrentes das relações entre o homem e a realidade objetiva e suas implicações no processo pedagógico. Os aspectos teórico-metodológicos do estudo centram-se na psicologia histórico-cultural e no materialismo histórico-dialético. Conclui-se que os processos ativos de apropriação do conhecimento, quando não consideram as relações lógico-históricas do desenvolvimento e da constituição do psiquismo humano, criam limitações a que o pensamento e a linguagem sejam potenciados pelo processo educativo. Decorre disso a necessidade de revisão dos referenciais teóricos presentes na formação de profissionais da educação e da psicologia em busca da finalidade maior da educação, que é o desenvolvimento das potencialidades humanas.
\end{abstract}

Palavras-chave: Pensamento e linguagem; atividade prática; psicologia histórico-cultural.

\section{THE THINKING ON THE PRACTICAL ACTIVITY: IMPLICATIONS IN THE PEDAGOGICAL PROCESS}

\begin{abstract}
The study presents a theoretical synthesis about the logic and forms of thought in practical activity as a consequence of relations between man and objective reality and its implications in the pedagogical process. The theoretical and methodological aspects of the study focus on the cultural-historical psychology and the historical dialectical materialism.It is concluded that the active processes of appropriation of knowledge, when it is not considered the logical historical development of relationships and the constitution of the human psyche, create limitations for the thought and language which are enhanced by the educational process. It follows from this the need to review the theoretical frameworks present in the 1 training of professionals in education and psychology for the higher purpose of education that is the development of human potential.
\end{abstract}

Key words: Thought and language; practical activity; cultural-historical psychology.

\section{LA REFLEXIÓN SOBRE LA ACTIVIDAD PRÁCTICA: REPERCUSIONES EN EL PROCESO PEDAGÓGICO}

\begin{abstract}
RESUMEN. El estudio presenta una síntesis teórica sobre la lógica y formas de pensamiento en actividad práctica como consecuencia de las relaciones entre el hombre y realidad objetiva y sus consecuencias en el proceso pedagógico. El teóricoaspectos metodológicos del estudio centrarse en psicología histórico-cultural y materialismo histórico dialéctico. Concluye que los procesos activos de propiedad del conocimiento, cuando no considerar relaciones lógico-histórico y de la constitución de la psique humana, crear limitaciones al pensamiento y la lengua son potenciados proceso educativo. Run-si la necesidad de la revisión de los marcos teóricos presentes en la formación de profesionales de la educación y la psicología en busca de mayor propósito de educación que es el desarrollo del potencial humano.
\end{abstract}

Palabras-clave: Pensamiento y el lenguaje; actividad práctica; psicología histórico-cultural.

Os processos ativos de ensino e de aprendizagem vêm sendo objeto de investigação em diferentes referenciais teóricos, focando ora as relações entre os estudantes e os objetos de estudo, ora as metodologias de ensino que criam, por meio da organização do ensino, situações que visam à apropriação ativa do conhecimento por parte dos estudantes e a mudanças positivas na qualidade da educação em geral.

Mesmo assim, verifica-se que a educação, nos diferentes níveis de escolarização, não vem cumprindo

Pedagoga, mestre e doutora em Educação pela Faculdade de Educação da Universidade de São Paulo. Professora doutora da Universidade de São Paulo e dos programas de pós-graduação em Educação (FEUSP) e Mudança Social e Participação Política (EACH USP). 
sua finalidade, que é criar, de forma sistematizada e intencional, condições para que os homens se apropriem do conhecimento elaborado historicamente e se humanizem.

Neste estudo, a partir dos pressupostos teóricometodológicos do materialismo histórico-dialético e da teoria histórico-cultural, são apresentadas algumas considerações sobre a constituição histórico-cultural do psiquismo humano no tocante aos processos educativos mediados pela atividade prática instituídos no contexto escolar.

A tese defendida neste texto refere-se ao fato de que as mediações simbólicas objetivadas nos processos pedagógicos devem criar condições para a superação do pensamento empírico decorrente da relação sensório-intuitiva e intuitivo-intelectual presente na atividade prática, quando esta se organiza a partir dos fundamentos da lógica formal. A apropriação dos conceitos na atividade prática pressupõe, segundo a lógica dialética, a superação do sentido pessoal elaborado pela ação perceptual no movimento ativo de elaboração desse sentido. Considera-se que devem ser priorizadas condições específicas para o desenvolvimento do pensamento teórico como uma das potencialidades humanas a serem objetivadas no psiquismo humano por meio dos processos educativos que medeiam o significado histórico e cultural dos objetos de estudo.

Em pesquisa realizada sobre as mediações simbólicas na atividade pedagógica que criam possibilidades de transformação da condição humana (Bernardes, 2006), seja do educador, seja do estudante, verifica-se que dois dos elementos determinantes na análise de ações pedagógicas que criam possibilidades para o desenvolvimento do pensamento teórico dos estudantes são a influência do conhecimento sobre o desenvolvimento e a constituição histórico-cultural das funções psicológicas superiores por parte dos educadores.

Assim, este texto tem como objetivo apresentar algumas reflexões sobre a relação entre linguagem e as formas de pensamento que se objetivam a partir das atividades práticas com os diferentes objetos sociais e pelas múltiplas relações possibilitadas nas atividades humanas, especialmente na atividade pedagógica (Bernardes, 2009; Moura, 2010), que sintetiza a unidade entre a atividade de ensino (Davidov, 1992, 1988) e a atividade de estudo (Leontiev, 1983).

Em síntese, o objeto deste estudo é a natureza social da constituição do pensamento e da linguagem, assim como das formas e da lógica do pensamento humano como elementos essenciais a serem contemplados no processo pedagógico que visa à superação da condição humana como produto das múltiplas relações criadas pela vida em sociedade.

\section{A LINGUAGEM COMO INSTRUMENTO CONSTITUTIVO DO PENSAMENTO}

Rivière (1988), ao sintetizar as elaborações vigotskianas sobre a concepção semiótica da consciência, resgata o conceito de linguagem utilizado originalmente na língua russa. "Myšlenie $i$ reč", traduzido como pensamento $e$ linguagem na linguagem ocidental, não resgata a concepção ampla utilizada por Vigotski. De acordo com Rivière (1988) $)^{1}$ :

O conceito de rec é amplo, e em Vygotsky se refere, sobretudo, à linguagem como atividade funcional, incluindo, portanto, um sentido muito pragmático, que se pode contrapor ao de linguagem como estrutura abstrata ou código analisável com independência de seu emprego interativo. Não se trata, portanto, da fala como realização motora, mas como atividade (deyatel 'nost') instrumental, situável no plano das unidades de análises da Psicologia, de que falava Vygotsky (p. 81) (SIC).

A referência ao significado da palavra linguagem geralmente utilizada por Vigotski identifica a inadequação do termo a uma simples estrutura semântica composta por códigos, sem função interativa. Inclui a perspectiva de a linguagem ter uma estrutura funcional e instrumental que possibilita aos sujeitos interagirem entre si. As funções da linguagem transcendem os limites da oralidade como ação motora, apontando-a como uma operação na atividade humana. Nesta abordagem psicológica, entende-se a linguagem como elemento constitutivo da consciência e como elemento presente nas relações do pensamento. Considera-se a linguagem como uma "atividade instrumental" essencialmente humana.

Como atividade, a linguagem deve ser entendida como uma unidade molar presente na organização das ações e operações do homem com a realidade objetiva. Como instrumento, identifica a presença de características essencialmente humanas, que possibilitam ao homem apropriar-se das elaborações históricas e culturais da sociedade, humanizando o próprio homem no mesmo processo em que transforma a sua própria constituição e conduta.

1 As citações das obras em língua espanhola contam no texto na forma de tradução livre. 
A atividade instrumental do homem, diferentemente da dos animais, assume caráter de processo social e é realizada coletivamente. Um exemplo clássico de atividade instrumental do homem é a caçada (Leontiev, 1970, 1983). Trata-se de uma ação coletiva movida pela necessidade do grupo de sujeitos que se organizam em ações individuais e coletivas com o objetivo de atingir um produto - a caça - que, por sua vez, será objeto de consumo da coletividade envolvida na atividade. As ações, sequenciadas e executadas pelos sujeitos em atividade, assumem características essencialmente humanas à medida que são planejadas e executadas coletivamente, superando a concepção instintiva própria dos animais. Na execução das ações, o homem faz uso de instrumentos que possibilitam a mudança de qualidade do próprio trabalho, que, por sua vez, dá origem à forma humana de reflexo da realidade, ou seja, a consciência.

No processo de constituição do homem, segundo Leontiev (1970), “a passagem à consciência é o início de uma etapa superior ao desenvolvimento psíquico. $\mathrm{O}$ reflexo consciente, diferentemente do reflexo psíquico próprio do animal, é o reflexo da realidade concreta ... que distingue as propriedades objetivas estáveis da realidade" (p. 75). Este processo, de acordo com os fundamentos do materialismo histórico-dialético, ocorre a partir do trabalho.

Ante as necessidades decorrentes da vida social, o homem organiza as ações individuais e coletivas em que o trabalho e a linguagem são constituídos como estímulos determinantes e essenciais para a constituição da consciência no homem. Inicialmente o trabalho é caracterizado pela fabricação de instrumentos e efetua-se na atividade coletiva. A linguagem é identificada como um instrumento mediador das concepções elaboradas socialmente e faz uso de signos, considerados instrumentos de relação entre as pessoas. No trabalho, as ações dos homens assumem duas funções, assim descritas por Leontiev (1970): "uma função imediatamente produtiva e uma função de ação sobre os outros homens, uma função de comunicação" (p. 92).

$\mathrm{O}$ conceito de instrumento, inerente à atividade instrumental, não deve ser compreendido apenas como um objeto de forma particular, com características físicas determinadas, mas também como um objeto social. No exemplo da caçada, a organização social presente na atividade coletiva faz uso, na ação executora de abater a caça, de objetos físicos que assumem também a característica de objetos sociais. No tocante aos objetos físicos presentes na atividade instrumental, concebe-se que, em sua criação e manutenção como ferramentas coletivas, assumem também características sociais, uma vez que o objeto em si é fruto da necessidade humana em geral. Pela transmissão de sua função aos herdeiros da cultura, o objeto constitui-se num instrumento com significado social. Trata-se de instrumentos materiais com significação social desenvolvidos na atividade humana que têm a função mediadora entre as pessoas e a realidade objetal.

A linguagem é considerada pela psicologia histórico-cultural como um instrumento social que faz uso de signos para estabelecer a comunicação entre os sujeitos. No exemplo da caçada, na atividade de trabalho os homens interagem entre si, o que torna necessária a comunicação entre eles. Os movimentos e os sons vocais decorrentes da interação dos homens assumem a função de mediação entre os sujeitos, ou seja, a função comunicativa.

Do movimento de interação entre as pessoas originam-se os signos, que se constituem também em instrumentos sociais que cumprem o objetivo primordial de possibilitar a comunicação entre os sujeitos. A função mediadora dos signos se estabelece na relação entre as pessoas. Dos gestos à linguagem sonora articulada, a linguagem se estabelece como instrumento social de comunicação.

Para os homens, a linguagem assume a característica de sistema de códigos que designam objetos externos e suas relações. De acordo com Luria (1987), “... com a ajuda desses códigos incluem-se os objetos em determinados sistemas de categorias. Esse sistema de códigos leva à formação da consciência "categorial"" (p. 26). Os signos pertencentes ao sistema social de códigos têm um conteúdo implícito que representa um objeto entre os demais e identificam características de uma categoria de objetos reconhecidos socialmente, diferentemente dos demais objetos.

O conteúdo da palavra, que identifica o significado social do objeto, é resultado do processo de consciência do homem na atividade instrumental. Identificando a relação entre a palavra e o seu conteúdo com a consciência do homem na atividade, Leontiev (1970) afirma:

$\mathrm{O}$ elo direto que existe entre a palavra e a linguagem, de um lado, é a atividade de trabalho dos homens, do outro, é a condição primordial sob a influência da qual eles se desenvolvem enquanto portadores do reflexo consciente e 'objetivado' da realidade. Significando no processo de trabalho, um objeto, a palavra distingue-o e generaliza-o para a consciência individual, precisamente 
na sua relação objetiva e social, isto é, como objeto social (p. 93).

Nas ações de trabalho e de interação entre os homens, a palavra representa o significado social na comunicação e faz uso do sistema de códigos vigente. Ao mesmo tempo, a palavra reflete a consciência individual da realidade objetiva, identificando o pensamento do homem em relação ao objeto social. Dessa forma, para Leontiev (1970), “a linguagem não desempenha apenas o papel de meio de comunicação entre os homens, ela é também um meio, uma forma da consciência e do pensamento humanos ... . Tornase a forma e o suporte da generalização consciente da realidade" (p. 93).

No movimento de análise da relação histórica existente entre o pensamento e a palavra, Vigotski identifica que existem momentos em que tais processos se integram e outros em que esse fato não ocorre. O significado da palavra é apontado pela psicologia histórico-cultural como a unidade que efetiva a integração entre os dois processos mentais. Segundo Vygotski (2001),

o significado da palavra ... é a unidade de ambos os processos, que não admite mais decomposição e sobre a qual não se pode dizer que representa: um fenômeno da linguagem e do pensamento (p. 289).

Como unidade integradora do pensamento e da linguagem verbal, o significado da palavra corresponde à generalização do conceito relacionado ao objeto social. Ao mesmo tempo em que é representativa do sistema social de códigos, como instrumento semiótico, a palavra representa um conceito elaborado, histórico e cultural, no processo social de apropriação da realidade objetiva. $O$ significado da palavra, diante da duplicidade da função semiótica, constitui-se num fenômeno verbal e intelectual. A integração entre os processos mentais por meio do significado da palavra é definida por Vygotski (2001) na seguinte afirmativa:

O significado da palavra é um fenômeno do pensamento somente na medida em que o pensamento está ligado à palavra e encarnado nela e vice-versa, é um fenômeno da linguagem somente na medida em que a linguagem está ligada ao pensamento e iluminado por ele. É um fenômeno do pensamento verbal ou da palavra com sentido, é a unidade do pensamento e da palavra (p. 289).
A possibilidade de compreender a relação entre o pensamento e a linguagem por meio da unidade presente no significado da palavra é de fundamental importância para a psicologia histórico-cultural; no entanto, Vygotski (2001) identifica que o traço mais importante, essencial na sua tese, refere-se à concepção de que "os significados das palavras evoluem” (p. 289). O autor aponta que a concepção evolutiva do significado da palavra constitui-se no elemento diferenciador das outras interpretações do fenômeno realizadas pela psicologia associativa; é o elemento que possibilita a superação da concepção de que a palavra e o significado ocorrem numa relação direta possibilitada pela concepção de associação de ideias.

Diante do elemento diferenciador próprio da psicologia histórico-cultural, concebe-se que o pensamento e a linguagem se integram a partir do significado da palavra. Também se deve considerar que o significado da palavra evolui à medida que os sujeitos se apropriam das elaborações culturais acerca da realidade objetal. Essa evolução ocorre diante das interações dos sujeitos ao longo das atividades humanas, caracterizando o desenvolvimento do pensamento no movimento de apropriação dos conceitos.

\section{ASPECTOS TEÓRICO-METODOLÓGICOS DA NATUREZA SOCIAL DO PENSAMENTO}

A natureza social do pensamento é identificada a partir das relações presentes nas categorias do materialismo histórico-dialético que se constituem como unidades de contrários compondo a totalidade das relações entre o ser humano e a realidade objetiva. Kopnin (1978) identifica algumas unidades que compõem a dimensão social do pensamento humano, a saber: o material e o ideal, o físico e o psíquico, o racional e não racional, o racional e o judicativo, assim como o intuitivo e o discursivo.

A relação entre o material e o ideal estabelece-se no movimento do pensamento e na produção humana centrada no material e no intelectual. A dialética entre as formas de produção ocorre em virtude de que o material é decorrente do processo de elaboração intelectual do homem nos meios de trabalho e a produção intelectual é elaborada pelo homem a partir das atividades materiais na realidade objetiva.

A matéria é concebida como o sensorialmente perceptível, ao passo que o ideal só existe como categoria contrária ao que é material decorrente da atividade prática humana de apropriação das relações objetivas com o mundo. No movimento de 
constituição do ideal, o pensamento atua como o ideal em relação ao objeto material nele refletido, mas, ao mesmo tempo, o ideal distingue-se do pensamento como forma pura. Nesta condição, o ideal se constitui como representação do material nos sistemas simbólicos.

Na lógica dialética, o material é concebido como o objeto que é apropriado intelectualmente pelo homem. Este processo ocorre por meio da mediação simbólica, que atribui sentido e significado ao conteúdo histórico do objeto, assim como pelas relações reais da pessoa como sujeito concreto e pelas circunstâncias objetivas pertencentes a esse processo. Decorrente desse movimento de abstração, constitui-se a imagem cognitiva do objeto no pensamento, e, pela linguagem, a imagem cognitiva assume a característica de ideal nas relações práticas humanas. $\mathrm{Na}$ comunicação, a imagem dos objetos tem a forma sensorial-material resultante do pensamento, como objeto ideal.

O ideal, como reflexo do objeto, é constituído por meio da percepção do mundo objetivo através dos órgãos dos sentidos, e estabelece a unidade entre $o$ fisiológico e o psíquico no pensamento, que, por sua vez, vincula-se à atividade do sistema nervoso do homem, traduzindo a relação entre a consciência e o cérebro.

$\mathrm{Na}$ psicologia histórico-cultural, a relação entre o físico e o psíquico estabelece-se num processo ativo do sujeito mediado pelas relações humanas, transcendendo a relação linear entre as unidades de contrários.

Leontiev (1983), nas investigações ontogenéticas sobre a percepção, introduz o conceito de ação perceptual, que requer um processo ativo por parte do sujeito na apropriação da realidade. A simples percepção sensorial do objeto é considerada insuficiente para a elaboração da imagem desse objeto, uma vez que o “... que os que percebem não são os órgãos dos sentidos, mas o homem com ajuda dos órgãos dos sentidos" (p. 46). Davidov (1988) resgata a conexão entre os órgãos dos sentidos e a percepção do mundo externo ao afirmar que "as formas do objeto como objeto material são postas a descoberto pelo homem na ação prática com aquele e somente em seguida passam ao plano da representação ideal" (p. 118).

O ideal, assim, assume a particularidade de ser produto da ação humana de análise e interpretação do real. Tal concepção é correlata ao posicionamento de Marx (1996), que considera o real como independente da consciência, da vontade e da intencionalidade humana, justamente por ser de constituição sócio- histórica, diferentemente da concepção hegeliana de ideal, que considerava o pensamento como criador do real.

Outra unidade de contrários própria da constituição do pensamento é o racional e o não racional, a qual assume caráter histórico em virtude do grau de domínio que o homem possui em relação à compreensão dos fenômenos, processos e objetos da realidade objetiva. Kopnin (1978) considera que a definição de racional ou não racional somente tem sentido "no momento em que o homem compara os produtos de sua atividade com as necessidades socialmente significativas e define em que medida esses produtos levam à realização dos seus objetivos" (p. 141). Como unidades constituintes do pensamento em movimento, o autor define o racional e o não racional como "momentos de um único processo de desenvolvimento da prática e do conhecimento do homem" (p. 141).

A superação do não racional em racional ocorre à medida que a humanidade e o pensamento do homem se desenvolvem. Resgata-se, assim, a concepção de movimento presente no materialismo históricodialético apontada por Kopnin (1978), considerandose que "sempre há resquícios do não racional e, se uma coisa deixa de ser tal qual era, surge forçosamente outra; o pensamento humano encontra permanentemente algo novo, algo que ainda não foi dominado pela razão e a prática nela baseada" ( $p$. 141).

O movimento de constituição do pensamento, enquanto um processo histórico de transformação do desconhecido em conhecido, cria novas possibilidades de entendimento da realidade e abre novas perspectivas e condições de entendimento e de compreensão do mundo pelo homem. A razão possibilita a superação do conhecimento dado, transformando o não racional em racional.

$\mathrm{Na}$ atividade humana, o homem transforma a realidade objetiva por meio de sua ação prática, e, segundo Kopnin (1978), a razão "dirige essa ação com o seu reflexo do objeto ativo e voltado para um fim. ... A razão pode ser definida como forma superior de conhecimento teórico da realidade" (p. 143). Por sintetizar o conhecimento, a razão constitui-se como um aspecto do racional que tem como base os conceitos e o estudo da natureza destes. O outro aspecto é o juízo, que tem como função avaliar e desmembrar as relações da realidade objetiva.

Tanto a razão quanto o juízo operam com abstrações, com conceitos elaborados por meio do processo de apropriação da realidade; no entanto, a razão além de transferir e agrupar as abstrações, 
também conscientiza o conteúdo e a natureza do objeto. O juízo não penetra no conteúdo e na natureza das abstrações, ele opera no limite de um esquema dado. Não obstante, Kopnin (1978) afirma que existe uma relação entre o juízo e a razão no desenvolvimento do pensamento teórico. Assim, o pensamento judicativo deve converter-se em racional. Numa relação em espiral, ao atingir maior grau de elaboração, a razão converte-se novamente em juízo, agora em uma nova qualidade.

No campo do conhecimento científico, o pensamento teórico desenvolve-se tanto no aspecto do racional quanto do judicativo. Como unidade de contrários, a razão e o juízo superam a condição do entendimento imediato acerca do objeto e se transformam em base para o desenvolvimento um do outro.

Além dos sentidos no movimento de apropriação dos elementos da realidade e da razão como balizadora das ações e operações das atividades humanas rumo a um fim, a intuição se faz presente como elemento integrante na elaboração do pensamento teórico. Segundo Kopnin (1978),

\section{... a dialética marxista não leva a intuição além dos limites do pensamento racional, baseado na experiência, mas a considera forma especial de pensamento teórico, mediante o qual se opera o salto no conhecimento do objeto, a interrupção da continuidade no movimento do pensamento (p. 148 itálicos do autor).}

É na atividade prática do homem que ocorrem os saltos intuitivos que promovem a elaboração de novas ideias e teses a respeito da natureza, ultrapassando os limites dados pelo conhecimento. Nesse aspecto, a intuição não assume conotação mística, mas é decorrente das relações teórico-práticas elaboradas pelo próprio homem, e exige, de acordo com Kopnin (1978), "todas as faculdades cognitivas do homem, da imaginação à sutileza e nela se deposita toda a experiência do desenvolvimento social e individual antecedente do homem" (p.149).

O pensamento intuitivo é concebido como decorrente da relação sensório-intuitiva, fruto das relações perceptuais do homem com a realidade, e ao mesmo tempo é intuitivo-intelectual, como elaboração da atividade racional constituída pela razão. No processo de desenvolvimento do pensamento intuitivo, a necessidade de sistematização e de comunicação assume caráter discursivo; no entanto, não é possível que as elaborações humanas se limitem à discursividade.
A inter-relação dos elementos constitutivos do pensamento forma a totalidade da constituição social do pensamento, como partes que compõem o todo. As unidades dialéticas presentes na constituição social do pensamento são postas em movimento e integram-se na totalidade do pensamento teórico, base do desenvolvimento do conhecimento científico.

\section{A LÓGICA E AS FORMAS DO PENSAMENTO NA ATIVIDADE PRÁTICA}

Nas construções teórico-metodológicas do materialismo histórico-dialético, a experiência com o mundo externo é considerada a base do desenvolvimento do próprio pensamento. Tal proposição indica que as sensações e a percepção são entendidas como unidades primárias na elaboração dos conhecimentos acerca do mundo exterior.

Não obstante, tais relações com o mundo objetivo não podem ser consideradas como as únicas formas de apropriação da realidade. $\mathrm{Na}$ atividade prática ocorre a percepção ativa, considerada por Leontiev (1983) como o primeiro e o principal ponto de vista da teoria do conhecimento; no entanto, o próprio autor salienta que seria incorreto considerar que toda atividade perceptiva decorra diretamente da atividade prática, indicando a percepção ativa visual e a auditiva como mediadas pelas significações sociais.

Ao relacionar o sensorial ao racional, Davidov (1988) considera que a experiência sensorial, como base do pensamento teórico, assume duas formas características. Para o referido autor, "a experiência sensorial de primeiro tipo se apóia nas observações e representações. A experiência de segundo tipo, incluindo de maneira peculiar a observação, se apóia na ação cognoscitiva, que descobre as conexões internas como fonte dos fenômenos observados" ( $p$. 138).

As duas formas existentes de percepção ativa da realidade não podem ser entendidas como excludentes, pois a percepção da realidade por meio de observações e representações constitui-se como a forma primária de percepção. Na dimensão da ação cognitiva, a percepção amplia as relações com o objeto material, estabelecendo-se por meio das conexões internas que constituem a base para a compreensão do objeto. Essa ampliação da percepção para além das relações externas do objeto é dada pela mediação das significações sociais que permeiam os objetos de uma forma geral na constituição do pensamento.

Segundo Leontiev (1983) e Davidov (1988, 1982), o fundamento do conhecimento é a base sensório-objetal apenas como a primeira forma de 
percepção, porém não a única. A forma perceptual ativa cognitiva inclui a mediação da percepção sensória, porém supera o imediatismo do objeto, incluindo suas significações. Estas relações são identificadas no campo da gênese do conhecimento por Leontiev (1983) como a abstração inicial do objeto.

No aspecto lógico, o conhecimento sensorial e o racional não podem ser associados diretamente ao empírico e ao teórico, pois ambos se constituem como níveis no movimento do pensamento. Apesar de serem considerados como níveis relativamente independentes, o empírico e o teórico constituem-se como unidade dialética no desenvolvimento do pensamento. No nível empírico de apropriação da realidade, o objeto é representado pelas suas manifestações exteriores decorrentes da contemplação viva, ao passo que no nível teórico o objeto reflete as relações internas e cognoscitivas do objeto.

Constata-se, em ambos os níveis de percepção da realidade objetiva, a presença do racional e do sensorial, que no pensamento assumem níveis de complexidades diferentes. Apontando a relativa independência e ao mesmo tempo a aproximação entre os níveis empírico e teórico do pensamento, Kopnin (1978) pondera que "a fronteira entre eles é condicional; o empírico se transforma em teórico e, ao contrário, o que em certa etapa da ciência se considerava teórico torna-se empiricamente acessível em outra etapa mais elevada" (p. 153).

Como particularidade da forma lógica de identificação das características externas dos objetos próprias da constituição empírica do pensamento, Pinto (1969) afirma que "a lógica formal está perfeitamente habilitada a dar conta dessa missão elementar" (p. 177); quando se buscam as relações superiores do pensamento nem sempre a lógica formal consegue ser suficiente, sendo necessária outra forma lógica para analisar o processo histórico e o movimento constituinte do próprio objeto. A superação da explicitação dos fatos pela lógica formal é dada pelo modo dialético de pensar. De acordo com Pinto (1969), a forma dialética constituinte do pensamento considerado como superior parte da reflexão de "que o homem pensante, a criatura lógica, que irá conhecer o mundo natural e explicá-lo, é ele próprio um produto desse mesmo mundo e tem de ser entendido, em todos os seus aspectos e funções, com as mesmas idéias gerais que explicam o processo total da realidade" (p, 184).

Como particularidade da lógica formal, o seu conteúdo reflete as propriedades e relações gerais dos objetos, fenômenos e processos da realidade objetiva, mas nem por isso deixa de ser amplo e complexo. Não se pode desconsiderar a importância tanto da lógica formal quanto da lógica dialética na constituição do pensamento e da linguagem no movimento de apropriação da realidade objetiva. Tal consideração se expressa na identificação de que a produção das ideias é dialética, uma vez que o processo evolutivo da própria ideia parte do movimento do conhecimento elaborado pelo homem; ao mesmo tempo, considera-se que a expressão da ideia é formal, pois, necessariamente, expõe-se pelas vias semânticas e semióticas elaboradas nos moldes formais.

A diferença substancial entre os dois sistemas de entendimento da realidade reside na forma como se organizam e no conteúdo que manifestam a partir da análise da realidade. A lógica dialética busca o entendimento dos fatos a partir dos juízos, conceitos, deduções, teorias e hipóteses como formas cognitivas de compreensão da realidade objetiva e suas relações. A lógica formal estuda a linguagem como meio de sua existência; estuda o conhecimento e o pensamento vinculados aos símbolos e operações.

Em busca de evidências sobre a inter-relação das formas de pensamento no processo de apropriação da realidade objetiva, considera-se que não basta ter clareza sobre a relação entre conceitos, juízos e deduções, mas, além disso, torna-se necessário definir as particularidades de cada um eles. Kopnin (1978), ao realizar o resgate histórico dos conceitos, das formas de pensamento, sintetiza-os na seguinte afirmação:

\footnotetext{
Os conceitos, juízos e deduções são diversos pelas funções que exercem no movimento do pensamento. $\mathrm{O}$ juízo serve para fixar rigorosamente certo resultado no movimento do pensamento, enquanto o conceito resume todo o conhecimento antecedente do objeto mediante a reunião de inúmeros juízos num todo único. Neste sentido o conceito atua como uma redução original do juízo, conservando todo o essencial no conteúdo destes; ao fixar o já obtido, ele se constitui num degrau de sucessivo movimento do pensamento. A dedução é uma forma de movimento do pensamento de uns juízos e conceitos a outros, traduz o processo de obtenção de novos resultados no pensamento. A dedução expressa o movimento, a transição do pensamento de uns juízos e conceitos a outros, de um conteúdo do conhecimento a outro (p. 193, itálicos do autor).
}

Ao identificar o juízo como resultado do movimento do pensamento e o conceito como o resumo de todo o conhecimento, não se indica, 
necessariamente, que os juízos sejam a base de qualquer reflexão sobre os objetos. Isso não significa que haja uma ordem ou uma sucessão histórica entre as formas de pensamento, pois a elaboração dos próprios juízos, muitas vezes, pauta-se em conceitos apropriados anteriormente, assim como a dedução se organiza a partir do movimento entre juízos e conceitos. Para a compreensão da constituição das formas de pensamento, deve-se considerar o movimento dialético existente entre essas formas. Não se pode afirmar que qualquer forma de pensamento anteceda ou suceda a outras. Evidencia-se, sim, o trânsito da dedução entre juízos na elaboração de conceitos, assim como a dedução também se relaciona aos conceitos na elaboração de novos juízos.

De acordo com Kopnin (1978), “a diferença entre os juízos, conceitos e deduções nos modos de expressão do conhecimento verdadeiro condiciona igualmente a diferença de conexão entre o singular e o universal que neles se manifesta ...” (p. 193). Assim, na dialética evidencia-se o juízo na relação entre o singular e o universal e o conceito na atenção principal centraliza-se no universal, ao passo que a dedução se verifica no como, no porquê e em que base o singular se relaciona com o universal.

Nas particularidades de cada forma de pensamento, o juízo é considerado como a forma mais simples do processo de apropriação da realidade, uma vez que identifica os aspectos gerais em toda abstração, seja nos conceitos seja nas deduções; já os conceitos são considerados juízos particulares que evidenciam a ideia do universal no fenômeno, e as deduções constituem-se como uma forma de mediação entre juízos e conceitos.

Neste estudo, a identificação e o entendimento da lógica e das formas de pensamento são utilizados como mediadores no processo de comunicação entre os sujeitos, assim como explicitam os modos pelos quais o pensamento se organiza tendo em vista as relações entre o homem e a realidade objetiva pela atividade prática.

\section{CONSIDERAÇÕES FINAIS}

Tendo-se como pressupostos da psicologia histórico-cultural que o pensamento se realiza na palavra e que o significado da palavra evolui (Vygotski, 2001), considera-se ser o contexto escolar um espaço de excelência para que tanto o pensamento quanto a linguagem, assim como todas as demais funções psicológicas superiores, possam ser desenvolvidos pela mediação do conhecimento na relação entre o ensino e a aprendizagem.
A partir desses pressupostos, entende-se que é na atividade pedagógica, unidade dialética entre as atividades de ensino e de estudo no contexto escolar, que o pensamento e a linguagem devem ser potencializados pela organização de ações planejada pelo educador e executada coletivamente, de forma ativa, por todos os sujeitos que integram o processo pedagógico.

$\mathrm{Na}$ educação básica, o conhecimento elaborado historicamente, como produto da atividade humana em geral, deve ser apropriado pelos estudantes, porém o movimento de internalização dos conceitos, segundo a psicologia histórico-cultural, ocorre de forma ativa tanto por parte dos estudantes quanto por parte do educador. As ações dos estudantes objetivam-se na relação sensório-intuitiva e intuitivo-intelectual. As ações do educador objetivam-se na organização do ensino que medeia o significado da palavra, o conceito. Tanto os estudantes quanto o educador devem estar em atividade prática, no caso particular da relação entre ensino e aprendizagem, a partir da lógica dialética, identificada aqui como atividade pedagógica.

Neste movimento dialético, as formas e a lógica do pensamento devem ser consideradas numa organização do ensino que tenha como finalidade o desenvolvimento das funções psicológicas superiores dos estudantes em atividade de estudo; no entanto, faz-se necessário que o educador tenha conhecimento do modo como as funções psicológicas superiores se constituem historicamente. Esta é uma condição necessária para que a atividade pedagógica seja duplamente objetivada - na organização do ensino e no desenvolvimento das funções psicológicas superiores -, em especial a do pensamento teórico e a da linguagem dos sujeitos que a integram.

Constata-se que na atividade prática realizada no processo de ensino e de aprendizagem em grande parte das escolas a palavra (o conceito) muitas vezes é a síntese de um objeto de estudo fragmentado, não historicizado, como algo que emerge de uma realidade imediata, como produto da ação isolada do homem. Muitas vezes os conceitos são estudados como representação do objeto em si. A lógica de ensino mais comum na escola, mesmo envolvendo de forma ativa os estudantes na apropriação dos conceitos, limita-se à lógica formal. A forma de pensamento mais frequente no processo de ensino e aprendizagem ativos assume a configuração de juízos elaborados sobre o objeto de estudo. A complexidade do pensamento raramente supera a condição de pensamento intuitivo, limitando-se às condições postas pelo pensamento empírico e não atingindo os níveis de 
pensamento teórico que se articulam entre juízos, conceitos e deduções de forma dialética.

A apropriação da realidade no esquema empírico é dada pela sequência percepção-representaçãoconceito. Neste sentido, a percepção da realidade e a representação dessa realidade na forma de conceito ocorrem na relação entre o geral e o universal. As propriedades comuns dos objetos são consideradas representações desse objeto a partir do processo comparativo que identifica suas propriedades gerais; no entanto, as percepções sensoriais somente possibilitam a identificação das propriedades gerais e externas do objeto, ou seja, do objeto em si, posto da realidade imediata, na qual se insere independentemente de qualquer conexão histórica do sistema integral do qual se constitui o conceito. Do movimento de análise do objeto decorre a síntese do conhecimento que faz uso de exemplos para identificar as classes de objetos. No movimento de identificação do real, a palavra é indispensável para a representação do objeto.

$\mathrm{Na}$ dialética materialista, a realidade complexa (o concreto) assume-se como ponto de partida e como ponto de chegada na produção do conhecimento, uma vez que é no movimento de reflexão e de identificação da essência do objeto que este se reconstrói, reelaborase no pensamento e sintetiza-se numa qualidade abstrata superior à anterior. A realidade complexa necessita estar relacionada aos demais elementos do real, fato que estabelece relação entre o singular e o universal. Como ponto de partida na produção do conhecimento, o concreto constitui-se como elemento abstrato, sem que sejam determinadas as suas peculiaridades; ou seja, é a própria realidade complexa. Por meio das abstrações iniciais decorrentes do processo de reflexão e de aproximação do movimento histórico constituinte do próprio objeto é que se chega ao concreto pensado como síntese das múltiplas determinações, como a realidade compreendida e transformada numa qualidade superior à anteriormente possível. Esse movimento de relação entre o universal (o próprio conceito em movimento) e o singular (próprio das particularidades do objeto), e vice-versa, é constituinte do pensamento teórico. Em síntese, Davidov (1988) afirma que "as propriedades da abstração inicial podem definir-se assim: é a conexão historicamente simples, contraditória e essencial do concreto reproduzido" (p. 143). A palavra, no movimento de apropriação da realidade, é entendida como meio simbólico e semiótico que atua como mediadora da atividade mental, como instrumento da linguagem natural ou artificial. $O$ significado da palavra é a generalização do conceito, é a essência do objeto em movimento.

Para que a linguagem e o pensamento possam ser potencializados na atividade pedagógica, as unidades de contrários presentes na natureza social do pensamento devem ser colocadas em movimento constante de superação em relação à condição momentânea dos sujeitos. Assim como o conceito, as generalizações e as abstrações, a palavra evolui no movimento de apropriação da natureza pelo homem, o pensamento e a linguagem, tanto dos estudantes quanto do educador, também devem desenvolver-se mediante o movimento de apropriação dos conteúdos históricos do objeto de estudo.

Ultrapassar as possibilidades de compreensão do objeto de estudo pela ação perceptual significa superar as possibilidades de elaboração de um sentido pessoal atribuído pelos estudantes no movimento ativo de elaboração do conceito. A apropriação do significado social dos objetos de estudo requer que o conceito seja compreendido para além das elaborações individuais e assuma a condição supraindividual presente no significado sócio-histórico e cultural da realidade.

Considerando-se os processos de ensino e aprendizagem independentemente de faixa etária, de nível e de forma de escolarização, o desenvolvimento psicológico dos sujeitos é potencializado pelas relações interpessoais possibilitadas nas atividades humanas. $\mathrm{O}$ processo de formação e de desenvolvimento dos sujeitos, possibilitado pela mediação do conhecimento elaborado historicamente, como condição universal do ser, objetiva-se pelas vivências com os objetos de estudo que criam possibilidades para que as abstrações iniciais possam mediar o processo dialético de constituição das funções psicológicas superiores em geral; no entanto, considera-se inadequado atribuir às vivências com os objetos de estudo a função de promotoras do desenvolvimento humano uma vez que toda relação com a realidade é mediada por significações sociais elaboradas numa dimensão histórica e cultural. Vivências e experiências, assim como emoções e sentimentos, são entendidas como necessárias ao processo de apropriação da realidade e de desenvolvimento psicológico. Não obstante, entendese que estas, sem a mediação das significações sociais dos objetos, dos fenômenos e dos fatos, não conseguem por si mesmas promover a apropriação da produção humana elaborada historicamente.

No movimento de apropriação dos conceitos e da própria realidade de forma dialética, o ponto de partida é a realidade complexa como produto da 
socialidade, mediada pelas abstrações que sintetizam as relações com as significações elaboradas historicamente no movimento dialético de produção e de apropriação da produção humana.

Considera-se que, em nenhum momento do desenvolvimento humano, as vivências com os objetos materiais e ideais possam ser excluídas do movimento de apropriação da realidade, pois são consideradas essenciais para a elaboração das abstrações iniciais necessárias para que o movimento dialético do pensamento e da linguagem se objetive entre juízos, conceitos e deduções.

Não se trata de priorizar as vivências ou as significações numa ordem hierárquica ou sequencial. Entendê-las desta forma seria fazer uso de uma lógica formal para analisar um fenômeno dialético de constituição histórica e cultural e o desenvolvimento do psiquismo humano pelas vias possíveis de apropriação da realidade objetiva.

Levando-se em conta as alterações no modo de organização do ensino e das possibilidades de intervenção na escola, tem-se que a função essencial dessa instituição seja promover o humano no homem pela via das relações entre o ensino e a aprendizagem de forma sistemática.

Independentemente de a escola cumprir tal função, fato questionado ante as dificuldades constatadas no sistema educacional brasileiro, considera-se necessário ter como referência que o sujeito que ensina e o sujeito que aprende são de constituição histórico-cultural e, para humanizarem-se, necessitam apropriar-se de objetos materiais e ideais produzidos historicamente.

Pontua-se, neste aspecto, a necessidade de se contemplar, na formação dos profissionais da educação, o conhecimento sobre o desenvolvimento social das funções psicológicas superiores, assim como dos pressupostos da atividade prática na formação dos conceitos, de tal forma que os educadores e estudantes possam integrar suas atividades particulares na atividade pedagógica.

Considera-se que levar em conta a relação entre as vivências e as significações sociais dos objetos de estudo integrados a um sistema de relações elaboradas histórica e culturalmente e considerar a natureza social do pensamento e da linguagem nos processos pedagógicos pela via da superação do pensamento empírico em pensamento teórico são as condições mínimas necessárias para que a escola encontre caminhos para, de fato, cumprir sua função, também histórica e cultural.

\section{REFERÊNCIAS}

Bernardes, M. E. M. (2006). Mediações simbólicas na atividade pedagógica: contribuições do enfoque histórico-cultural para o ensino $e$ aprendizagem. Tese de doutorado Não-publicado, Universidade de São Paulo, São Paulo, SP.

Bernardes, M. E. M. (2009). Ensino e Aprendizagem como unidade dialética na atividade pedagógica. Psicologia escolar $e$ educacional, 13(2), 235-242.

Davidov, V. V. (1982). Tipos de generalización en la enseñanza. Habana, Cuba: Pueblo y Educación.

Davidov, V. V. (1988). La enseñanza escolar y el desarrollo psíquico: investigación psicológica teórica y experimental. Moscu: Progresso.

Kopnin, P. V. (1978). A dialética como lógica e teoria do conhecimento. Tradução: Paulo Bezerra. Rio de Janeiro: Civilização Brasileira.

Leontiev, A. N. (1970). O desenvolvimento do psiquismo. São Paulo: Moraes.

Leontiev, A. N. (1983). Actividad, conciencia, personalidade. Habana: Pueblo y Educación.

Luria, A. R. (1987). Pensamento e linguagem: as últimas conferências de Luria. Porto Alegre, RS: Artes Médicas.

Marx, Karl. (1996). O capital: crítica da economia política (Vol.1). 15a. ed. Tradução: Reginaldo Sant'Anna. Rio de Janeiro, RJ: Bertrand Brasil.

Moura, M. O. de. (2010). A atividade pedagógica na teoria históricocultural. Brasília: Liber livro.

Pinto, A. V. (1969). Ciência e existência: problemas filosóficos da pesquisa científica. Rio de Janeiro: Paz e Terra.

Rivière, A. (1988). La psicología de Vygotski. 3a. ed. Madrid: Aprendizaje Visor.

Vygotski, L. S. (2001). Obras escogidas (Vol. 2) Madrid: Machado Libros.

Endereço para correspondência: $\quad$ Maria Eliza Mattosinho Bernardes. Av. Senador vergueiro, n. 779 ap. 91 , Jardim do Mar, CEP 09750000, São Bernardo do Campo-SP. E-mail: memberna@usp.br. 